\title{
A cross-sectional study to assess the difference in perception of day surgery information between patients and medical staff in China
}

This article was published in the following Dove Medical Press journal: Patient Preference and Adherence

\author{
Xiaoqian Dengl,* \\ Shuqing Liang ${ }^{2, *}$ \\ Hui Li' \\ Divakara Gouda ${ }^{3}$ \\ Tao Zhu' \\ Kun $\mathrm{Xiao}^{4}$ \\ 'Department of Anesthesiology, \\ West China Hospital of Sichuan \\ University, Chengdu, Sichuan, People's \\ Republic of China; ${ }^{2}$ Department of \\ Anesthesiology, The First Affiliated \\ Hospital of Jinan University, \\ Guangzhou, Guangdong, People's \\ Republic of China; ${ }^{3}$ University of \\ Pennsylvania, Philadelphia, PA, USA; \\ ${ }^{4}$ School of Information and Software \\ Engineering, University of Electronic \\ Science and Technology of China, \\ Chengdu, Sichuan, People's Republic \\ of China \\ *These authors contributed equally \\ to this work
}

Purpose: The development of day surgery in China is still in its infancy. The aim of this study is to examine the difference in perception between patients and medical staff about day surgery and to find out what kind of information should be delivered to patients perioperatively.

Methods: The study was designed as a cross-sectional study using survey questionnaires. Patients undergoing day surgery and medical staff working in the day surgery center received a preoperative teaching questionnaire (PTQ). The PTQ consisted of preoperative, operative, postoperative and anesthesia information. Participants were asked to rate accurately what day surgery information they perceived as important on a five-point Likert-type scale that ranged from very important to not important. The main outcome was the value patients and staff place on perioperative information. Results: For patients, details of anesthesia (82.6\%) was the most important day surgery information, while for medical staff, preoperative (58.1\%), postoperative $(60.7 \%)$ and anesthesia $(60.0 \%)$ information were of the same importance. Patients ranked surgery effect $(83.3 \%)$ and pain management $(82.5 \%)$ as two of the top five most important details about day surgery, but these were not listed in the top 5 rankings of staff. Student's $t$-test results of mean rankings also showed that patients placed more importance on surgery effect $(4.8 \pm 0.6,4.6 \pm 0.6, P=0.036)$ and pain management $(4.8 \pm 0.5,4.5 \pm 0.5, P=0.031)$ than the medical staff did.

Conclusion: In China, day surgery is an emerging practice with both patients and medical practitioners still lacking experience, so high-quality perioperative teaching is necessary and important. Our study examining patients and staffs' views on day surgery information should be considered when developing perioperative teaching programs. To increase patient satisfaction of the day surgery experience, delivery of patient-specific information tailored to individual circumstances is necessary.

Keywords: day surgery, perception, perioperative teaching, anesthesia, pain management

\section{Introduction}

Due to advances in technology and treatment alternatives, the practice of day surgery is rapidly expanding, in China and internationally. ${ }^{1}$ Day surgery is an emerging method of ambulatory surgery that provides both a high-quality practice and benefits. In some developed countries, day surgery accounts for more than $80 \%$ of elective surgery ${ }^{2}$ however, in China, it accounts for only $20 \%{ }^{3}$ Inadequate facilities, inexperienced management and an insufficient supporting system are a few factors that contribute to this. Day surgery is only applied to a few, limited types of surgery and mainly performed in major teaching medical centers in metropolitan cities. The development of day surgery in China is still in its infancy.
Correspondence: Kun Xiao School of Information and Software Engineering, University of Electronic Science and Technology of China, Xiyuan Avenue, West Hi-Tech Zone, Chengdu, Sichuan Province 6II73I, People's

Republic of China

Tel +86 I38 8I77 | I69

Fax +86288320 2525

Email xiaokun@uestc.edu.cn 
Day surgery means that patients arrive at the hospital on the day of surgery and are discharged the same day to manage their recovery at home. This type of restructured surgical care presents a challenge to medical staff to provide perioperative teaching to patients in a reduced time frame and to provide information which will be most useful to their preoperative preparation and postoperative care activities at home. ${ }^{4}$ Insufficient perioperative information provision, delayed recovery of physical function, increased complications and pain after surgery are to be expected in day surgery. ${ }^{5}$ In China, there is no general practitioner-based referral system and patients have to recover at home without the aid of a medical practitioner, which makes perioperative patient teaching more important. Perioperative teaching is essential for day surgical patients to increase their awareness of the procedure and to prepare them for postoperative recovery. Mounting evidence demonstrates the positive clinical outcomes of perioperative patient teaching, such as reduced anxiety and pain as well as reduced postoperative complications. ${ }^{6,7}$

But what and how to deliver information to patients undergoing day surgery is a great challenge to medical staff. To this end, we have designed questionnaires for patients and medical staff to analyze their perioperative information needs. The aim of this study is to examine the difference in perceptions between patients and medical staff about day surgery and to find out what kind of information should be delivered to patients perioperatively.

\section{Methods}

The study was conducted using a questionnaire survey in the West China Hospital, Sichuan Province, China. The hospital was founded in 1892 and is one of the country's leading general hospitals. It is affiliated to Sichuan University, which has been selected as a national clinical and education base by the Ministry of Health, China. It has 7,800 employees and 38 clinical departments providing complete medical services covering all clinical areas. ${ }^{8}$ Because it is the most highly regarded hospital in southwestern China, it copes with an ever-increasing demand for surgery, for this reason, the Center for Day Surgery was created. This survey study was reviewed and approved by West China Hospital. Written informed consent was obtained from all patients in the anesthesia clinic. Patients who were undergoing day surgery received a predesigned questionnaire and finished them in 10 minutes with the help of nurses. Patients had to meet the following criteria to be included: be 18 years of age or older, have an education above primary school, and have no reading or hearing disability. All nurses and physicians who met the inclusion criteria were also asked to participate in the survey. Nurses were included if they worked in the ambulatory suit or ambulatory postoperative anesthesia care unit. Physicians were included if they are anesthesiologists, surgeons or physicians specializing in internal or general medicine, and worked in the day surgery center.

The questionnaire was designed for patients and medical staff and consists of three parts. The first part asks for general information of the patients and medical staff. The second part is a preoperative teaching questionnaire (PTQ). ${ }^{9}$ Participants were asked to rate accurately what day surgery information they perceived as important on a five-point Likert-type scale that includes ratings from 5 (very important) to 1 (not important). It is used to determine the value patients and staff place on perioperative teaching. Nine of the PTQ items address preoperative information, seven address operative information, five address postoperative information, and five address anesthesia information. The last part is how patients receive and how medical staff communicate the information above as well as how satisfied they were with perioperative teaching. Cronbach's alpha coefficients for the 26 items for perioperative teaching received by patients and valued by staff were 0.911 and 0.846 , respectively. These coefficients compared well with the 0.84 and 0.88 coefficients reported by Bernier et al in 2013. ${ }^{10}$

\section{Statistical analyses}

Data analysis was performed with SPSS 13.0 (IBM Corporation, Armonk, NY, USA) for Windows. Categorical variables are expressed as absolute and relative frequencies and quantitative variables are expressed as means and standard deviations. Demographic data of patients and medical staff were collected and performed with descriptive statistics. Percentage of agreement was calculated by the percentage of participants scoring from 1 to 5 on each question. Student's $t$-test was used to explore possible significant differences between patients' and medical staffs' ratings. A $P$-value of 0.05 or less was regarded as statically significant.

\section{Results}

\section{Demographics of study participants}

The demographic characteristics of patients and day surgery center staff are presented in Tables 1 and 2. A total of 82 patients who fulfilled the inclusion criteria were invited to take part in this study. Eighty of these patients completed and returned the questionnaires. The response rate was $97.6 \%$. Most responses were from women $(72.5 \%)$, with ages ranging from 25 to 61 and a mean age of $36.0 \pm 8.0$. Most of the patients have a college education (66.2\%). 
Table I Patient demographic data $(\mathrm{n}=80)$

\begin{tabular}{|c|c|c|}
\hline & Number & Percentage \\
\hline \multicolumn{3}{|l|}{ Gender } \\
\hline Female & 85 & 72.5 \\
\hline Male & 22 & 27.5 \\
\hline \multicolumn{3}{|l|}{ Age, years } \\
\hline$<30$ & 27 & 33.8 \\
\hline $31-40$ & 32 & 40.0 \\
\hline $4 I-50$ & 17 & 21.2 \\
\hline$>50$ & 4 & 5.0 \\
\hline \multicolumn{3}{|l|}{ Education } \\
\hline Primary school & 6 & 7.5 \\
\hline Middle school & $\mathrm{II}$ & 13.8 \\
\hline High school & 10 & 12.5 \\
\hline College & 53 & 66.2 \\
\hline \multicolumn{3}{|l|}{ Surgery type } \\
\hline Urinary & 35 & 44.8 \\
\hline Hernia & 28 & 35 \\
\hline Laparoscopic & 2 & 2.5 \\
\hline \multicolumn{3}{|l|}{ cholecystectomy } \\
\hline Varicose veins & 2 & 2.5 \\
\hline Mole removal & I & 1.2 \\
\hline Breast abscess & 3 & 3.8 \\
\hline Orthopedic & 9 & 11.2 \\
\hline \multicolumn{3}{|c|}{ Number of times patients } \\
\hline \multicolumn{3}{|c|}{ admitted to hospital } \\
\hline I & 57 & 71.3 \\
\hline 2 & 18 & 22.5 \\
\hline 3 & 2 & 2.5 \\
\hline 4 & 2 & 2.5 \\
\hline 5 & I & 1.2 \\
\hline
\end{tabular}

Most patients reported being admitted to hospital once (71.3\%). Urinary surgery (43.8\%) and hernia surgery $(35.0 \%)$ were the first and second most common surgery types among these patients. Patients with two and more admissions were asked to finish the questionnaire only at their first admission to day surgery center. Thirty medical staff working in the day surgery center were invited and completed the survey. The average age was $29.4 \pm 7.1$ years. Their mean amount of day surgery work experience was $3.4 \pm 5.7$ years with a range from less than 1 year to 30 years. Their average total work experience was $5.7 \pm 6.7$ years. About $73.4 \%$ of the staff had bachelor's or higher degrees.

Importance rating of patients and staff to the overall information about day surgery

Participants' perception of the importance of information during day surgery are shown in Figure 1. For patients, details of anesthesia is the most important among the four dimensions of day surgery information (Figure 1A). However, in the opinions of medical staff, preoperative, postoperative and anesthesia information are of the same importance (Figure 1B). The five most important details about day surgery as rated by patients were surgery safety (91.3\%), postoperative recovery $(88.8 \%)$, anesthesia safety $(87.5 \%)$, surgery effect $(83.3 \%)$ and pain management $(82.5 \%)$. Medical staff working in the day surgery center rated differently, reporting that postoperative recovery (90\%), anesthesia safety $(83.4 \%)$, preoperative medication management $(83.3 \%)$, and surgery safety $(80 \%)$, preoperative examination $(80 \%)$, and preoperative fasting $(80 \%)$ were the five most important information areas. The summary of the top five most important information areas ranked by patients and staff area are shown in Table 3 .

\section{Comparing the perceived prominent information of daily surgery information between patients and staff}

When the opinions of patients and staff on the importance of certain information were compared using the Student's $t$-test, statistically significant differences were detected for the following 10 dimensions: 1$)$ surgery effect $(P=0.036)$, $2)$ surgery cost $(P=0.001), 3)$ surgery time $(P=0.032)$, 4) preoperative examination $(P=0.001), 5)$ preoperative nervousness $(P=0.007), 6)$ preoperative fasting $(P=0.000)$, 7) preoperative medication management $(P=0.000), 8)$ what to wear prior to operation $(P=0.001), 9)$ what to eat prior to operation $(P=0.026), 10)$ pain management $(P=0.031)$.

Table 2 Staff demographic data $(n=30)$

\begin{tabular}{|c|c|c|}
\hline & Number & Percentage \\
\hline \multicolumn{3}{|l|}{ Gender } \\
\hline Female & 23 & 76.7 \\
\hline Male & 7 & 23.3 \\
\hline \multicolumn{3}{|l|}{ Age, years } \\
\hline$<30$ & 19 & 63.3 \\
\hline $31-50$ & 10 & 33.3 \\
\hline$>50$ & 1 & 3.4 \\
\hline \multicolumn{3}{|l|}{ Education } \\
\hline General equivalency diploma & 8 & 26.6 \\
\hline Undergraduate & 11 & 36.7 \\
\hline Graduate & 11 & 36.7 \\
\hline \multicolumn{3}{|l|}{ Title } \\
\hline Nurse & 12 & 40.0 \\
\hline Resident & 9 & 30.0 \\
\hline Attending & 8 & 26.7 \\
\hline Chief & I & 3.3 \\
\hline \multicolumn{3}{|l|}{ Working experience, years } \\
\hline$<1$ & 11 & 36.7 \\
\hline $\mathrm{I}-5$ & 8 & 26.6 \\
\hline $6-10$ & 5 & 16.7 \\
\hline$>10$ & 6 & 20.0 \\
\hline \multicolumn{3}{|l|}{$\begin{array}{l}\text { Ambulatory working experience, } \\
\text { years }\end{array}$} \\
\hline$<1$ & 14 & 46.7 \\
\hline $1-5$ & 10 & 33.3 \\
\hline $6-10$ & 5 & 16.7 \\
\hline$>10$ & I & 3.3 \\
\hline
\end{tabular}



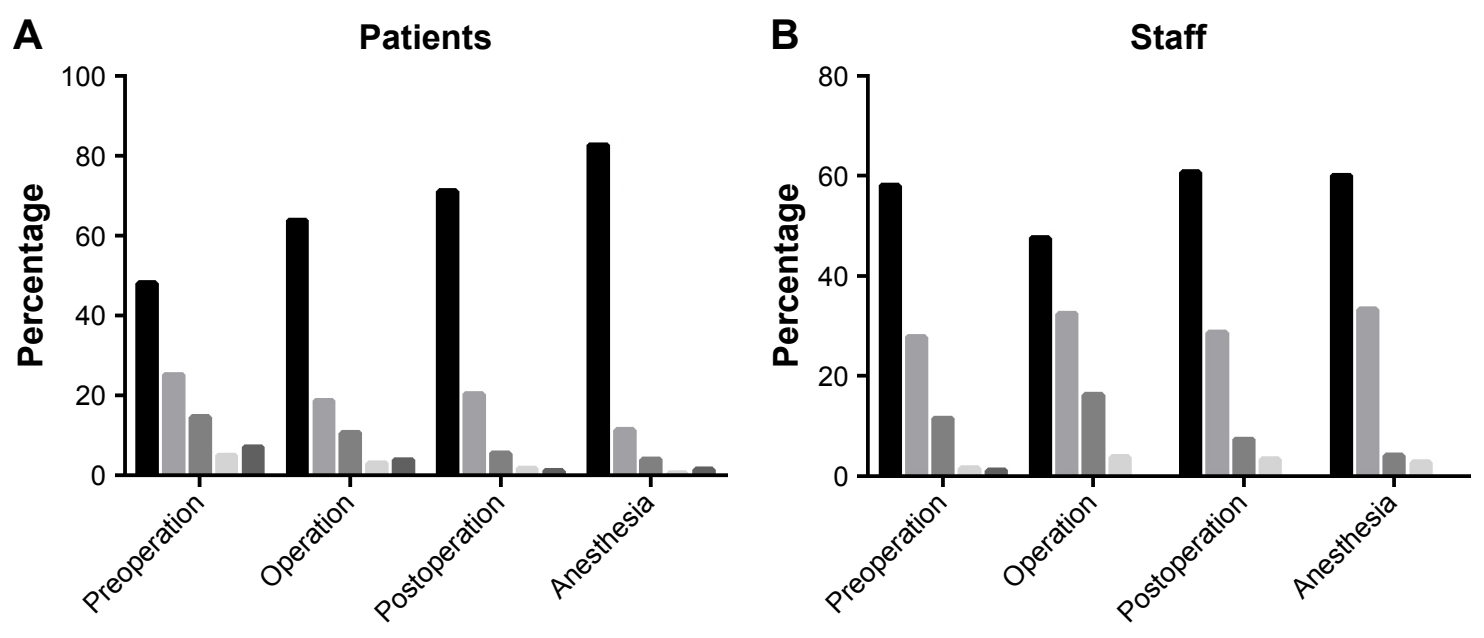

Very important $\longrightarrow$ Moderately important $\square$ Important Somewhat important important

Figure I Participants' perception of the importance of information during day surgery.

Notes: Anesthesia details were the most important among the four dimensions of day surgery information for patients (A); whilst for medical staff, preoperative, postoperative, and anesthesia information were of the same importance (B).

Among all the differences shown above, only surgery effect and pain management were considered more important to patients than to medical staff. Details are shown in Table 4.

\section{Preferred methods of perioperative teaching and satisfaction of patients and staff}

Both patients and staff preferred oral delivery of information about day surgery. Overall, about $41.8 \%$ patients were satisfied with the perioperative information they received, but only $5 \%$ of medical staff working in the day surgery center were satisfied with the information they were delivering to patients.

\section{Discussion}

Our aims were to examine the difference in perception between patients and medical staff about day surgery in China and to find out what kind of information should be delivered to patients as perioperative teaching. Patients undergoing day surgery focus more on anesthesia details, especially postoperative pain management, among all perioperative information. Medical staff, on the other hand, thought

Table 3 Top 5 most important information as ranked by patients and staff

\begin{tabular}{l|l|l}
\hline Ranking & Patients & Staff \\
\hline Top I & Surgery safety (91.3\%) & Recovery (90\%) \\
Top 2 & Recovery (88.8\%) & Anesthesia safety (83.4\%) \\
Top 3 & Anesthesia safety (87.5\%) & Premedication (83.3\%) \\
Top 4 & Surgery effect (83.3\%) & Surgery safety (80\%) \\
Top 5 & Pain management (82.5\%) & Examination (80\%) \\
\hline Note: Percentage values show the proportion of participants who ranked "5" or \\
"very important" on the preoperative teaching questionnaire question.
\end{tabular}

all information about day surgery is of great importance, especially preoperative fasting, examination and perioperative medication management.

\section{Patients were not satisfied with the perioperative information teaching}

As day surgery patients undergo surgery and stay in hospital for less than 24 hours, it is of critical importance to give useful information about day surgery during the perioperative period. In our clinical practice, however, it

Table 4 Student's t-test results of mean ranking between patients and staff

\begin{tabular}{l|l|l|l|l}
\hline & Groups & Mean \pm SD & Percentage $^{\mathrm{a}}$ & P-value \\
\hline Surgery effect & Patients & $4.8 \pm 0.6$ & 83.3 & 0.036 \\
& Staff & $4.6 \pm 0.6$ & 63.3 & \\
Surgery time & Patients & $4.2 \pm 1.1$ & 55.0 & 0.032 \\
& Staff & $4.4 \pm 0.7$ & 50.0 & \\
Examination & Patients & $4.2 \pm 1.1$ & 60.0 & 0.001 \\
& Staff & $4.7 \pm 0.6$ & 80.0 & \\
Preoperative & Patients & $3.8 \pm 1.3$ & 40.0 & 0.007 \\
nervousness & Staff & $4.4 \pm 0.7$ & 53.4 & \\
Preoperative & Patients & $4.2 \pm 1.1$ & 58.8 & 0.000 \\
fasting & Staff & $4.8 \pm 0.4$ & 80.0 & \\
Preoperative & Patients & $4.2 \pm 1.1$ & 57.5 & 0.000 \\
medication & Staff & $4.8 \pm 0.4$ & 83.3 & \\
management & & & & \\
What to & Patients & $3.7 \pm 1.3$ & 37.5 & 0.001 \\
wear prior to & Staff & $4.0 \pm 0.8$ & 30.0 & \\
operation & & & & \\
What to eat prior & Patients & $4.0 \pm 1.2$ & 47.5 & 0.026 \\
to operation & Staff & $4.5 \pm 0.7$ & 56.7 & \\
Pain management & Patients & $4.8 \pm 0.5$ & 82.5 & 0.031 \\
& Staff & $4.5 \pm 0.5$ & 56.7 & \\
\hline
\end{tabular}

Note: aThe percentage of patients and medical staff ranking "very important". 
seems that patients are not very satisfied with our perioperative teaching work, with only $41.8 \%$ of patients reporting that they were satisfied with the information they received. In a study by Alacadag and Cilingir, ${ }^{11}$ patients argued that they received less knowledge than they felt they expected about the day surgery process before the actual surgery. One of the reasons was limited time for staff to communicate to the patients preoperatively. In China, due to increasing outpatient workload and a serious shortage of medical resources, ${ }^{12}$ a specialist has to see around 100 patients per day. The time spent with each patient is very limited - usually less than 3 minutes. ${ }^{13}$ Undoubtedly, this contributes to patient dissatisfaction and the deterioration of doctor-patient relationships. The issue gets exacerbated further when applied to day surgery in China, which is still very much in a start-up stage. Patients are unfamiliar with the day surgery mode and always want to receive more perioperative information. Medical staff, meanwhile, lack experience in this type of surgery compared to medical personnel in developed countries.

\section{Perceptions of day surgery information are different between patients and medical staff}

Our results show that among the four dimensions of perioperative information, anesthesia information holds the highest percentage of most important rankings by patients. Another study found the same conclusion. ${ }^{14}$ A study of 150 female participants undergoing day surgery for gynecological conditions revealed the three areas of greatest concern to patients were anxiety related to being under anesthesia, being unconscious during the procedure and experiencing pain in the postoperative period. ${ }^{14}$ Evidence suggests that patients who receive information about anesthesia prior to the procedure benefit in terms of anxiety, symptoms, length of stay and perceptions of control. ${ }^{15}$ Information on anesthesia is valued very highly by patients $(82.6 \%)$, but medical staff pay less attention to it $(60 \%)$ in our survey. Under current practice, day surgery patients need to undergo preoperative anesthetic assessment. Nurses may consider the responsibility of providing anesthesia information is to be the anesthetist's. The time of contact between anesthetist and patient, however, is short, so information cannot be fully communicated by the anesthetist during this preoperative visit. Nurses in the day surgery center also have the responsibility to deliver preoperative anesthesia information to patients.

Our survey showed that among the top 5 importance rankings of patients and medical staff, patients valued pain management as a top 3 , but it was not listed on the top 5 rankings of staff. Postoperative pain, which up to $80 \%$ of patients reported to suffer after discharge, ${ }^{16}$ is seldom life threatening, but it can lengthen the time of recovery, resumption of normal activity and often causes delayed discharge and readmission. ${ }^{17}$ Unlike in-patients, day surgery patients have to recover at home and manage pain by themselves with their families. More knowledge about postoperative pain management is very necessary for these patients. ${ }^{18}$ Patients themselves request information about ways to control pain. ${ }^{11}$ But in a study by Suhonen and Kilpi, ${ }^{19}$ patients reported the information they received was inadequate. In our survey, patients valued postoperative pain management $(82.5 \%)$ more highly than medical staff $(56.7 \%)$ did. Medical staff should deliver more specific and tailored information about pain management to patients during perioperative teaching. In China's day surgery centers, the duty of perioperative teaching, especially pain management information, is neither clearly the responsibility of physician nor the nurse, which leads to insufficient information delivery to patients. The management of postoperative pain is also not patientcentered, with the postoperative analgesia being relatively simple. Oral non-steroidal drugs are mainly used. Another shortcoming of our pain management is that the telephonebased follow-up mode is often unable to get patient feedback in a timely manner. ${ }^{20} \mathrm{~A}$ better pain management strategy is critically needed to improve China's day surgery.

Perceptions differ between patients and medical staff on the importance of preoperative preparation, such as preoperative examination, preoperative medication management, and fasting in our survey. These information areas ranked top 5 in medical staff's value, but it seems that patients pay little attention to them. Mark Mitchell's study also found that information deemed most important by nurses was checking fasting time, checking medication and ensuring the presence of test results. ${ }^{9}$ However, some patients fail to comply with the request of fasting before surgery in clinical practice. A potential reason for this is a lack of understanding of the reason for fasting. ${ }^{21}$ Insufficient preoperative information about fasting may be the major cause. Among educational leaflets which were to be used across 267 anesthesia departments in the UK, only 27 mentioned preoperative fasting, and only 18 explained why fasting necessary. Preoperative medication management for patients, especially for patients with hypertension and diabetes, is very important. In our study, only $57.5 \%$ of patients value it as very important information compared to $83.3 \%$ of medical staff. The main reason why patients are not aware of the importance of preoperative preparation is because perioperative teaching 
does not address it adequately. There is, thus, a critical need to better inform day surgery patients about the importance of preoperative preparation.

\section{Methods of information delivery}

In this study, both patients and staff preferred to use faceto-face oral explanation as a method of information delivery because it is the most effective and feasible method as well as the currently clinically used method. But in this survey, only $5 \%$ of medical staff were satisfied with their work. Surprisingly, another study revealed that about $60 \%$ of nurses were satisfied with their oral explanation to patients. ${ }^{22}$ The reason may be that, in Hong-Kong, nurses have much more time to communicate to patients, so they can deliver more detailed information about day surgery. To better deliver perioperative information to patients, medical staff should adopt a few initiatives. Since face-to-face communication between patients and medical staff is limited, information delivery tools that save time and improve efficiency such as mobile applications like WeChat (a popular platform in China) and video chat should be utilized by medical staff to send tailored information to patients. Patients could follow the instructions communicated to them to make themselves better prepared for day surgery. We can thus reduce the burden on medical staff as well as improve the quality of perioperative education.

\section{Limitations}

This study had several limitations that could have influenced the outcomes. The relatively small sample size may affect the results. Patients and medical staff in this study were recruited from only one large day surgery center in West China Hospital, so generalizability may be limited. The majority of patients undergoing day surgery in China are younger patients with mild conditions. In our study, most of the surveyed patients were between 30 and 40 years old. These patients have higher educational levels and better compliance, which is not reflective of the general population.

\section{Conclusion}

In China, day surgery is still an emerging practice that most patients and medical staff lack experience with. High quality perioperative teaching is, thus, of great necessary and importance. Our study examining patient and staff views on day surgery information is an important resource to the development of perioperative teaching programs. To increase patient satisfaction during the day surgery experience, delivery of patient-specific information tailored to individual circumstances is very necessary. To this end, we should try to design APPs for day surgery based on the results of this survey. Patients could get more detailed day surgery perioperative information to make themselves better prepared, and better postoperative recovery management information to guide them as they recover at home.

\section{Acknowledgments}

This project was supported by Sichuan Science and Technology Program (Grant No 2018ZR0245) and Young Scientists Fund of the National Natural Science Foundation of China (Grant No 71704119). The sponsors had no involvement in this research.

\section{Author contributions}

All authors contributed toward data analysis, drafting and critically revising the paper, gave final approval of the version to be published, and agree to be accountable for all aspects of the work.

\section{Disclosure}

The authors report no conflicts of interest in this work.

\section{References}

1. Toftgaard C. Day surgery activities 2009: international survey on ambulatory surgery conducted 2011. Ambul Surg. 2012;17(3):53-63.

2. Gilmartin J, Wright $\mathrm{K}$. The nurse's role in day surgery: a literature review. Int Nurs Rev. 2007;54(2):183-190.

3. Yan D, Hongsheng M. Current status of day surgery care development in China. West China Med J. 2015;30(5):801-803.

4. Hälleberg Nyman M, Nilsson U, Dahlberg K, Jaensson M. Association between functional health literacy and postoperative recovery, health care contacts, and health-related quality of life among patients undergoing day surgery: secondary analysis of a randomized clinical trial. JAMA Surg. 2018;153(8):738-745.

5. Gilmartin J, Wright K. Day surgery: patients' felt abandoned during the preoperative wait. J Clin Nurs. 2008;17(18):2418-2425.

6. Asilioglu K, Celik SS. The effect of preoperative education on anxiety of open cardiac surgery patients. Patient Educ Couns. 2004;53(1):65-70.

7. Oshodi TO. The impact of preoperative education on postoperative pain. Part 2. Br J Nurs. 2007;16(13):790-797.

8. Deng X, Ye L, Wang Y, Zhu T. A cross-sectional study to assess the feasibility of a short message service to improve adherence of outpatients undergoing sedation gastrointestinal endoscopy in the People's Republic of China. Patient Prefer Adherence. 2014;8:1293-1297.

9. Mitchell M. Day surgery nurses' selection of patient preoperative information. J Clin Nurs. 2017;26(1-2):225-237.

10. Bernier MJ, Sanares DC, Owen SV, Newhouse PL. Preoperative teaching received and valued in a day surgery setting. AORN J. 2003; 77(3):563-572.

11. Alacadag M, Cilingir D. Presurgery anxiety and day surgery patients' need for information. J Perianesth Nurs. 2018;33(5):658-668.

12. Fu Y, Schwebel D, Hu G. Physicians' Workloads in China: 1998-2016. Int J Environ Res Public Health. 2018;15(8):1649.

13. Li Q, Xie P. Outpatient workload in China. Lancet. 2013;381(9882): 1983-1984.

14. Mitchell M. Patient anxiety and modern elective surgery: a literature review. J Clin Nurs. 2003;12(6):806-815. 
15. Hadjistavropoulos HD, Dobson J, Boisvert JA. Information provision, patient involvement, and emotional support: prospective areas for improving anesthetic care. Can J Anesth. 2001;48(9):864-870.

16. Apfelbaum JL, Chen C, Mehta SS, Gan TJ. Postoperative pain experience: results from a national survey suggest postoperative pain continues to be undermanaged. Anesth Analg. 2003;97(2):534-540.

17. Sveinsdottir H, Borgthorsdottir T, Asgeirsdottir MT, Albertsdottir K, Asmundsdottir LB. Recovery after same-day surgery in patients receiving general anesthesia: a cohort study using the quality of recovery-40 questionnaire. J Perianesth Nurs. 2016;31(6):475-484.

18. Fahmy N, Siah J, Umo-Etuk J. Patient compliance with postoperative analgesia after day case surgery: a multisite observational study of patients in North East London. Br J Pain. 2016;10(2):84-89.
19. Suhonen R, Leino-Kilpi H. Adult surgical patients and the information provided to them by nurses: a literature review. Patient Educ Couns. 2006;61(1):5-15.

20. Jaensson M, Dahlberg K, Eriksson M, Grönlund Å, Nilsson U. The development of the recovery assessments by phone points (RAPP): a mobile phone APP for postoperative recovery monitoring and assessment. JMIR Mhealth Uhealth. 2015;3(3):e86.

21. Walker H, Thorn C, Omundsen M. Patients' understanding of preoperative fasting. Anaesth Intensive Care. 2006;34(3):358-361.

22. Tse KY, So WK. Nurses' perceptions of preoperative teaching for ambulatory surgical patients. J Adv Nurs. 2008;63(6):619-625.

\section{Publish your work in this journal}

Patient Preference and Adherence is an international, peer-reviewed, open access journal that focuses on the growing importance of patient preference and adherence throughout the therapeutic continuum. Patient satisfaction, acceptability, quality of life, compliance, persistence and their role in developing new therapeutic modalities and compounds to optimize clinical outcomes for existing disease states are major areas of interest for the journal. This journal has been accepted for indexing on PubMed Central. The manuscript management system is completely online and includes a very quick and fair peer-review system, which is all easy to use. Visit http://www. dovepress.com/testimonials.php to read real quotes from published authors.

\footnotetext{
Submit your manuscript here: http://www.dovepress.com/patient-preference-and-adherence-journal
} 